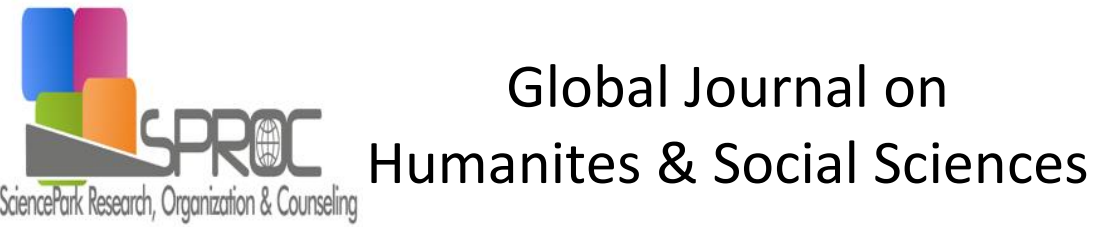

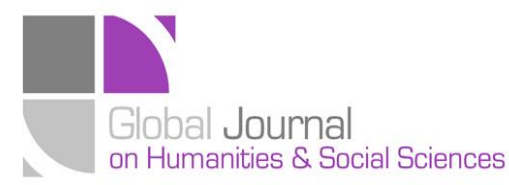

Vol 3 (2015) 216-223

Selected Paper of 4th World Conference on Design and Arts, (DAE-2015)

26-28 June 2015, St.Petersburg Christan University, St. Petersburg, Russia.

\section{fhettfe ctiq $q$ ti $q$ tc in qt $c$ f eq tfh th $f$ tco c flitf}

fhc q o fh Department of Graphic Design, Faculty of Fine Arts, Hacettepe University, Ankara 06590, Turkey.

flttff tetiq

Soyluçiçek, S. (2016). The association of typography with form and content in digital games, Global Journal on Humanites \& Social Sciences. [Online]. 03, pp 216-223. Available from: http://sproc.org/ojs/index.php/pntsbs

Received January 05, 2015; revised March 17, 2015; accepted April 10, 2015.

Selection and peer review under responsibility of Prof. Dr. Milan Matijevic.

(C)2016 SciencePark Research, Organization \& Counseling. All rights reserved.

\section{C tftcet}

The aim of this study is to define the correct usage of the connection between the typographic elements in digital games and the form and content of game concept. In this work, the points to take into consideration while utilizing this connection correctly and the effective usage of typographic elements with game graphics will be scrutinized. Along with the character, object and environment design that is composed of the story and concept design which underlies the game design, the selection of the typeface in games is also one of the points to be considered. The typographic elements are substantial design elements of a game design along with the character, environment and level design. The typographic elements of a game are helpful to enable the connection between the user and the game and to direct the user in the game. In this sense, from the game's opening scene, the selection of typefaces that are used in logos, menus, and directions increases in importance. Moreover, in both visual and technical manners the usage of typography in games brings different approaches compared to the ones used in the printed media. To illuminate these topics, successful game examples will be analyzed. The selection of typefaces used in the examples will be looked at from the point of subject, concept and audience and the principles of the correct usage of typography will be mentioned. Along with these, the rareness of the resources about the usage of typography in game design raises the importance of this work.

Keywords: Game design, typography, type face, user interface design.

ADDRESS FOR CORRESPONDENCE: fhc q o fh Department of Graphic Design, Faculty of Fine Arts, Hacettepe University, Ankara 06590, Turkey. E-mail address: seza@hacettepe.edu.tr / Tel.: +90-312-297-8825 
Soyluçiçek, S. (2016). The association of typography with form and content in digital games, Global Journal on Humanites \& Social Sciences. [Online]. 03, pp 216-223. Available from: http://sproc.org/ojs/index.php/pntsbs

\title{
ttqf ethq
}

In common with character, environment and level designs, typographic elements are a game's significant elements as well. A game's typographic elements are essential design items as they help the connection between the user and the game occur and help the user to be guided during the game. Typographic adjustments in games can be displayed in digital environments and this subject is evaluated in screen typography. Typographic applications in games that are included in the scope of screen typography require various adjustments in terms of legibility, readability, esthetics and appropriateness.

There are some distinct characteristics that distinguish screen typography from pressed ones. Texts and visuals that are displayed in digital environments are screened via monitors through the integration of lighted up picture elements. Texts consist of pixels that are displayed in 72 to $96 \mathrm{dpi}$ resolution and red, blue and green dots. Readers have different types of experiences through texts that are displayed on screens compared with a printed format. They can focus their eyes on paper with markings on it. Yet in a digital environment, readers focus on a screen that is spreading light waves. This, in long-term readings, can be quite tiring to the eyes (Rabinowitz, 2006). Nowadays pixelization issues are put away by high definition LCD televisions and monitors. Yet still texts in the screens need to be adjusted in different ways and made more legible. Furthermore, the compatibility between typography and product, the selection of typeface and the aesthetic appearance of it are of the most vital subjects that need to be examined.

According to Sarıkavak (2003), that typefaces hold many selection opportunities makes the selection of one 'suitable' character harder. The design philosophy of each typeface or their effects on page might not be known beforehand by all and the expression that they come up with depending on the design might not be displayed. For this reason, when selecting a typeface, aesthetic appearance, readability, legibility and suitability need to be taken into consideration. Typographic elements of digital games are displayed on monitors and the texts on monitors require different adjustments than the printed texts.

According to Sarıkavak (2007), on this matter,

\begin{abstract}
"Even though printed typography and color based functional applications form a frame in terms of graphic design, due to the limitations of computer screens it cannot be applied directly. The differences between these two environments become clear especially when legibility issues occur. Choices related to typography such as typeface selection, typesetting selection, spacing connections and line blanking determination should be made in accordance with the environment. Structural and geometric properties of a typeface that are designed for the print media, when displayed in a screen with 72 dpi resolution, is frequently incompatible with the screen grid in terms of legibility. Grid pattern leads to an intermingling of each letters, numbers and similar marks along with the missing structural features of a typeface. Moreover, even the spacing in typographic applications of the print media falls behind in a screen."
\end{abstract}

When these opinions are used as base, game and typography association and typography's suitability and acceptance by the user are one of the issues that should be discussed carefully when designing a game. The selection of typeface of the texts to be used in the game scenes, its alignment, type size, color and animation should form completeness with the content. A game's target audience and their age range is one of the factors that determine the type size that will be used in the game. In addition to the readability of the text, the selection of typeface that is suitable for the game's genre, structure and concept helps the game's visuals and typographic elements integrate. In this sense, in game design the correct usage of the typographic elements used in the game from the game's logo and entrance scene till the last scene helps an authentic language to be created in the game. 


\section{efh flift ctiti $q$ tc e flufh fh ttfctfh tfh fh to tfff}

In a game design, the scenes that typographic elements are used frequently in are the user interfaces. According to Pardew (2004), the user interfaces represents the information that allows the player to control the game and receive feedback). The user interfaces are scenes that connect the user and the game and give information about the course and the situation of the game. In these scenes texts are frequently used. Scenes in which typographies are used are as listed below.

- Intro scenes

- Menus

- Instructions

- Controls

- Heads up display

- Credits

Games' user interfaces generally include design items and instructions like loading screen, main menu, information screen, settings, toolbars, time, score indicators and credits. These all are design items that are used throughout the game and needed in terms of guidance. The design of each varies by the game's genre and content.

The interface designs of games are classified in two titles - diegetic interfaces and non-diegetic interfaces. Diegetic interfaces are scenes that the user sees and belong to the game world. As the player moves around the world, all of the characters, objects and environments are included in the diegetic interface class. This king of interfaces lets the users focus more on the game and immerse themselves in the world of the game they're playing. Non-diegetic interfaces, on the other hand, are the most frequently used items in the majority of the games. The interfaces of this class include vi2(am)p.

and lud items tats give64( )-45(.)13(n)3(fo)-4(rm)-3(a112(tio)-5(n1)4( )-45(ab)4(o)-5(u)3(t)9( )--5(the)10( )45[(p)3rfo)6 
According to Moore (2011), who does a similar classification with Mitchell in the user interface design, the user interface includes 'in-game interface' and 'shell interface' (2). The in-game screens include the game playfield, the character, the objects like weapons and statistical items. The information on these screens might from time to time be static or active. The shell screens include the installation screens, the main title screens and the end of game screens and they give textual information about the game. Yet they aren't directly used. Shell interfaces, on the other hand, include the installation screens, menu items and the end of game screens and they give important textual information about the game. Users can bring up these screens to save their recent position or change the settings for the game. The typography usage in shell interfaces can be seen frequently. To be able to guide the user, it needs to be legible besides having an aesthetic appearance.
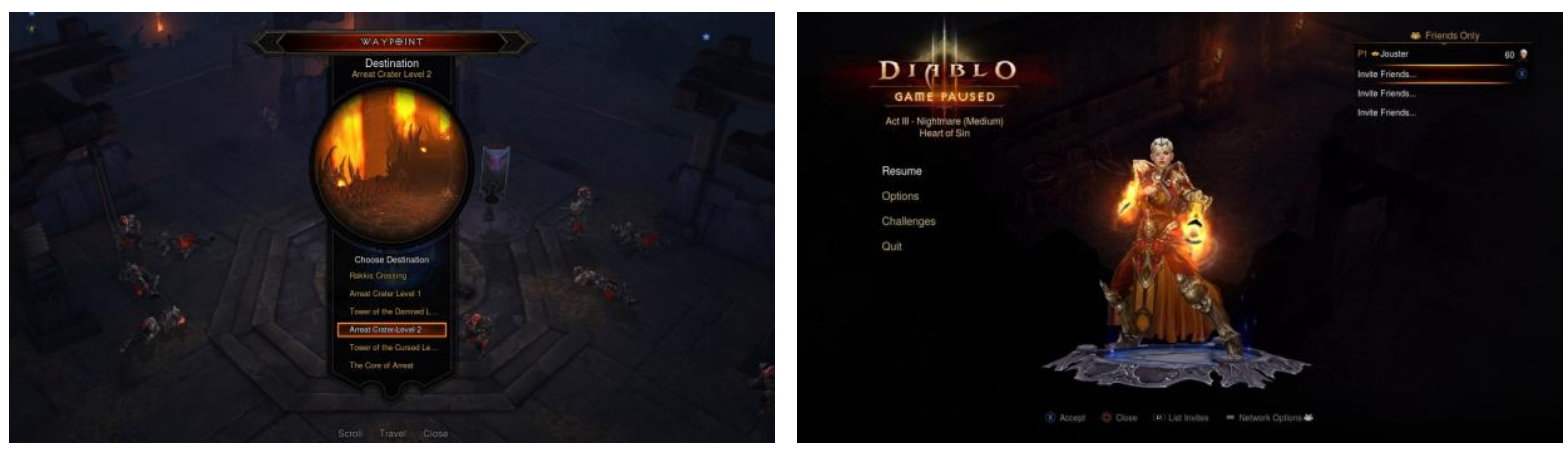

Figure 2: An example of shell interface design.

Another interface design in which typography is used is spatial user interface. In this kind of interface, user interface elements can be displayed in a three dimensional geometrical environment. User interface elements also transfer the information in the fictional game. Spatial user interface show similarity to the holograms used in the game Dead Space (3a). The game Heavy Rain (3b) can be shown as an example to this. In the game when the character wears a pair of advanced forensic glasses he can pick out details in the environment. As the character's visual angle is enhanced, the user can perceive the visualized information in the environment clearly and proceed in the game (Fagerholt \& Lorentzon, 2009).
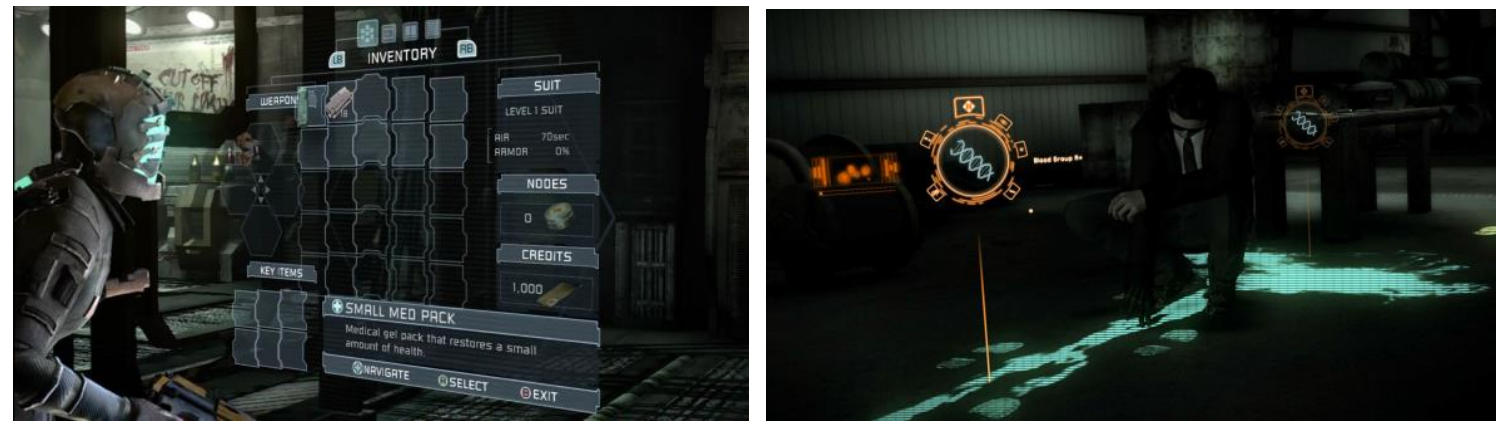

Figure 3a: An image from Dead Space's hologram scene - Figure 3b: Environmental user interface of Heavy Rain

Spatial user interface is the page in which the user can still see all the information and guidance without drifting apart from the game when the game is paused. By this means the user does not drift apart from the game and can still read the necessary information and proceed in the game. The displayed information is communed with the game world and located in accordance with aspect of the 
environment. In the game Splinter Cell Conviction, the fact that the typographic adjustments are considered as important draws attention. And the game is one of those games that are successful in projecting images integrated into the game environment (4). In some of the game scenes, projected texts on places in the environment also draw attention. The texts give the necessary information without preventing the game process. The texts used in the sample scene are commune with the environment design and they give the information to the user successfully*.

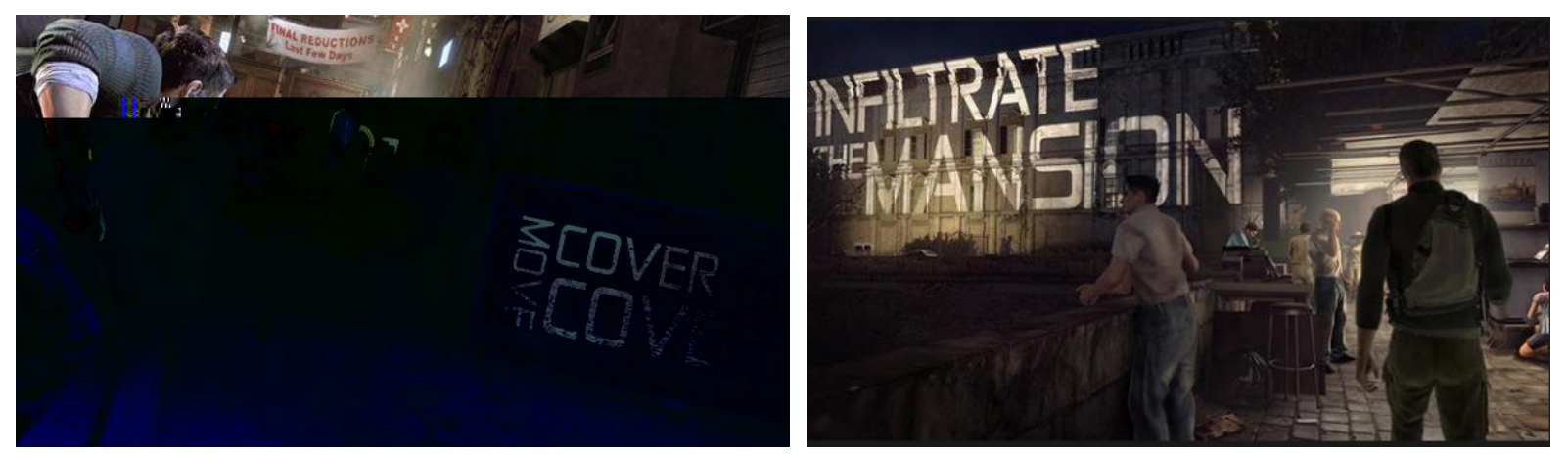

Figure 4: A screenshot of Splinter Cell Conviction

Splinter Cell Conviction is a TPS (Third Person Shooter) game the genre of which is adventure/war. 

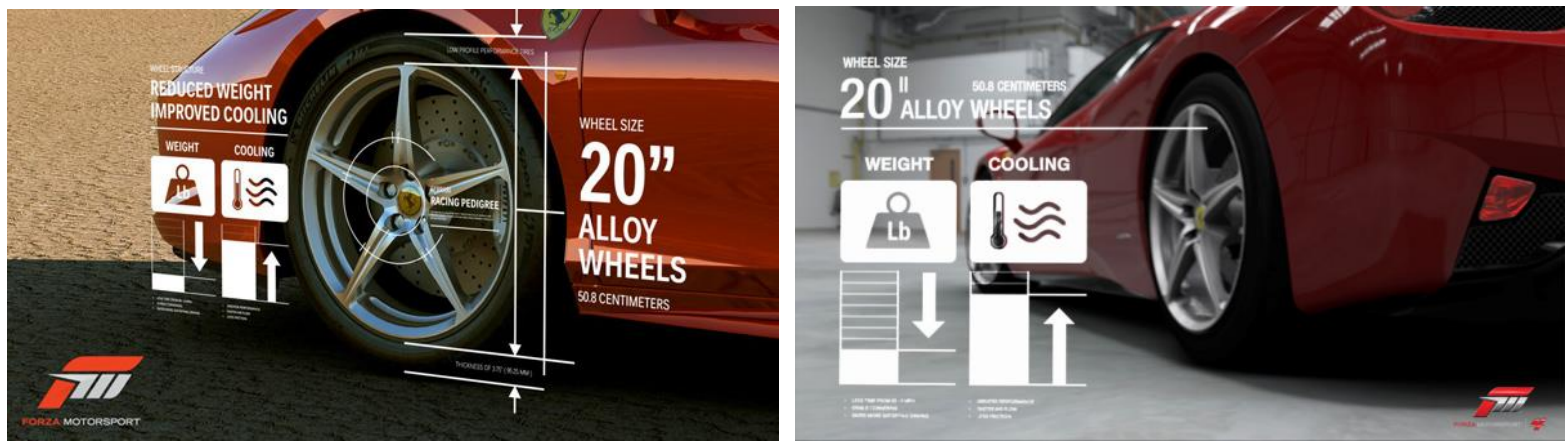

Figure 5: Scenes from 'Forza 4'

Another successful instance is the game Remember Me. The game which is released to the market by Capcom as both a PC and PS game is of the adult-oriented adventure game genre. In some scenes of the game some typographic elements appear to inform the user (6). It can be said that the texts that give information about the objects around and serve as an information design is designed conveniently for the atmosphere and the target audience of the game. These typographic elements are legible. They are located according to the angle and perspective of the game's camera and supported with pictographic elements.

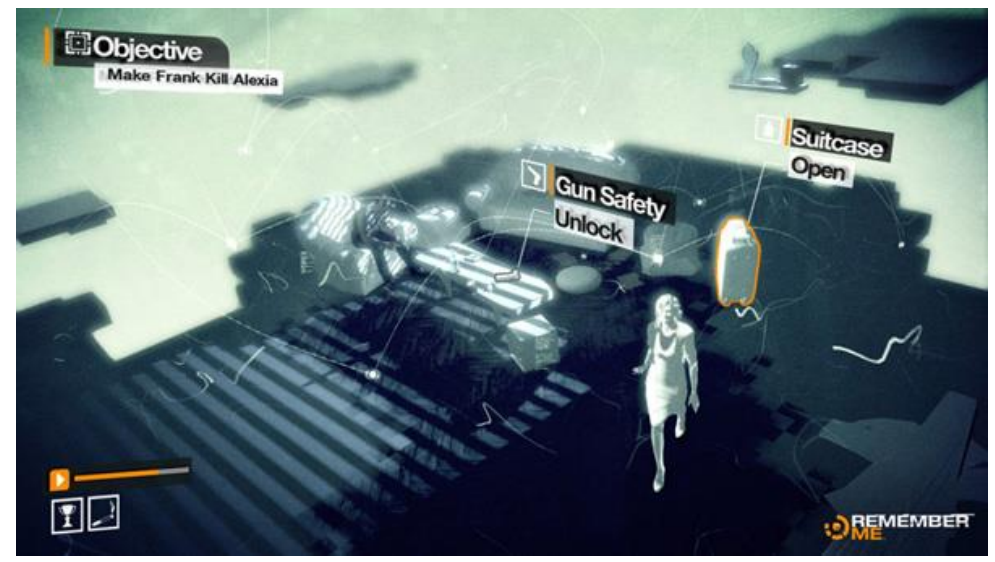

Figure 6: An image of the interface of Remember Me

\section{q ttftq $c$ fh tqCeeq tictiti fh fhcefh flefletiq $c$ f $C$ oc efh tc fh}

The selection of the typeface to use in a game should be done by taking the game's genre, structure, content and target language into consideration. During the selection stage, the subjects like aesthetics, appropriateness, readability and legibility should also be taken into consideration.

\subsection{Aesthetic and Appropriateness}

In game design, as in all graphic designs, aesthetic, appropriateness and legibility in typefaces are mostly neglected. Sarıkavak (2003) defends the opinion that while selecting a typeface, not only one's logic but also one's feelings should be involved in the decision. He emphasizes that not only the good appearance of the font but also the effect its typographic use makes is important. Additionally, the chosen typeface has characteristics that should be appropriate. It has to be acceptable by the audience and compatible with the product. 
In an interview with Robert Quigley about the typography in video games, Quigley stated that visual inconsistency in video games ruins the game typography. He claims it is a result of the lack of knowledge of the art directors who work for the development firms of the typographically problematic games. He also stated that this problem could be avoided by having typographic education but also by keeping up with the new information. Quigley claims that a good art director knows that Bank Gothic font shouldn't be used in a sci-fi game. Bank Gothic is mostly used in old sci-fi games in which cowboy characters and old steam machines are frequently used. On the other hand, as Hendel Gothic is a font of 70s, he claims that it is more appropriate when it is used in sci-fi games .

\subsection{Legibility and Readability}

Legibility and readability are different terms. Legibility relates to type forms and how easy it is to distinguish each letters and characters in certain forms. Readability, on the other hand, relates to type forms and their positions and logical placements on a page. There are many factors that may affect this, such as the choice of font, size, color, the use of space and the arrangement of the typography within that space. The way in which the text is presented is also a factor in readability, for example, whether typography is viewed on screen, page or within a dedicated exhibition space with ambient lighting (Ellison, 2006).

According to Felici (2003), legibility refers to a reader's ability to easily recognize letterforms and the word forms built from them (We don't read by recognizing one letter at a time, but by recognizing the shapes of while words and phrases). Readability refers to the facility and comfort with which text can be comprehended. Text with good readability must also be legible, but mere legibility doesn't make text readable. A book is much more likely to be a "page turner" if its type is pleasantly readablebadly set type wears a reader out.

Descriptions of readability and legibility go both for press media products and for design products seen on monitors. Readers recognize words by their shapes. The negative space around letter forms is very important in terms of legibility. As low resolution computer monitors cause legibility and readability difficulties, providing extra negative space can be regarded as an important way to promote letter and word recognition. Providing adequate negative space around text increases the readability and legibility because low resolution screens are tiring for the eyes. Various factor combinations must be considered by designers to create a balanced relationship between negative and positive spaces in a composition. Some of these factors are monitoring, guidance, size, texture and color.

The distance between the game platform and the user is changeable and determinant in a design. For instance, while the distance between the user who plays games on PC and the monitor must be around $30-50 \mathrm{~cm}$, the distance between the user who plays console games on TV must be around 2.5$3 \mathrm{~m}$. Typographic adjustments in the user interface designs for PC games may not have the same legibility level in console games. Or typographic designs for console games may be inappropriate for mobile games. According to the screen's distance, type size and type kerning may have to get increased.

\section{q eo tfq}

It is emphasized that typographic applications in games are frequently used in user interface designs. Interface designs in digital games may sometimes be one of the most difficult parts of developing a game. The reason for it is that most of the guidance and the information that must be

\footnotetext{
" http://www.themarysue.com/video-game-fonts-ray-larabie-interview/
} 
given may have to get placed in a small zone. While placing the information in the small zone, many design problems occur. With the help of the aesthetic approaches of the designs made in the zone, by designing more perceivable interfaces, controlling the game becomes much easier. Weak design of user interfaces leads to limitations in terms of user experiences even though it is a game that has a well-designed concept. Typographic adjustments used in interfaces are also of the factors that determines the success in in-game communications. Texts in video games must be adjusted according to their place and purpose of use. What is important is to provide readability and legibility of texts within the frame of aesthetics and appropriateness. In addition to these, typographic elements must be created in accordance with game graphics. Used typographic elements must not distract the user in the game scene yet it must not be too illegible and in the background either to not go unnoticed by the user. The selected typeface must represent the game's aura and match the game concept and content.

In this study the compatibility between the typographic adjustments in digital games and the game's form and content is examined. Screen typography is mentioned by looking at the general rules of typography and the changeable cases of these rules in game design are discussed. The fact that typographic adjustments of press media require different approaches than screened digital games is emphasized. To examine the designs of this field in different perspectives, to be aware of the limitations of a game design and to know the advantages it creates help the designer with finding aesthetic solutions to problems.

\section{fhfltfh efltf}

Ellison, A. (2006). The Complete Guide to Digital Type: Creative Use of Typography in the Digital Arts. New York:

Axis Publishing.

Fagerholt, E. \& Lorentzon, M. (2009). Beyond the HUD. User Interfaces for Increased Player Immersion in FPS

Games. Master thesis, Department of Computer Science and Engineering, Chalmers University of

Technology, Gothenburg.

Felici, J. (2003). The Complete Manual of Typography. USA: Adobe.

Mitchell, L. B. (2012). Game Design Essetials. Canada: John Wiley \& Sons Inc.

Moore, M. E. (2011). Basics of Game Design. USA: Taylor\&Francis Group.

Pardew, L. (2004). Game Design For Teens. Boston : Thomson Course Technology.

Rabinowitz, T. (2006). Exploring Typography. USA: Delmar, Cengage Learning.

Sarıkavak, N. K. (2003). Çağdaş Tipografinin Temelleri. Ankara: Seçkin Yayıncılık.

Sarıkavak, N. K. (2007). Görüntülükte Sayısal Font Sorunları - I. Sanat Yazıları, 15: 9-24. 